\title{
ESTRESSE ENTRE PROFESSORAS DO ENSINO FUNDAMENTAL DE ESCOLAS PÚBLICAS ESTADUAIS
}

\author{
Edward Goulart Junior \\ Marilda Emmanuel Novaes Lipp ${ }^{\#}$
}

\begin{abstract}
RESUMO. O artigo relata pesquisa que visou, entre outros objetivos, identificar a presença do estresse, a sintomatologia e as fases apresentadas pelos professores de $1^{\mathrm{a}}$ a $4^{\mathrm{a}}$ série do Ensino Fundamental atuantes em escolas públicas estaduais de uma cidade do Interior de São Paulo. Participaram do estudo 175 professores, perfazendo, aproximadamente, $70 \%$ dos profissionais de Ensino Básico I (PEB-I) em atuação no município. Para obtenção dos objetivos foram utilizados dois instrumentos de coleta de dados: o ISSL (Inventário de Sintomas de Estresse) e um questionário para caracterizar a população pesquisada. A pesquisa revelou que 56,6\% dos professores estão experimentando estresse, cujos principais sintomas presentes são: sensação de desgaste físico constante, cansaço constante, tensão muscular, problemas com a memória, irritabilidade excessiva, cansaço excessivo, angústia/ansiedade diária, pensar constantemente em um só assunto e irritabilidade sem causa aparente.
\end{abstract}

Palavras-chave: estresse, ensino fundamental, professoras.

\section{STRESS IN TEACHERS FROM GOVERNMENT PUBLIC SCHOOLS OF FUNDAMENTAL EDUCATION}

\begin{abstract}
Research identifies stress, symptomatology and its phases in government public school teachers of fundamental education working at state schools in an interior city of the state of São Paulo, Brazil. One hundred and seventyfive teachers, comprising $70 \%$ of the Basic Education professionals working in the municipality, participated in the study. Two data collection were employed: the Stress Symptom Inventory (SSI) and a questionnaire to characterize the researched population. Results show that $56.6 \%$ of teachers suffer from stress. Predominant symptoms comprise a worn-out sensation, constant tiredness, muscular tension and memory problems, excessive irritability, excessive tiredness, daily anxiety, constant thoughts on a single theme and irritability without any apparent cause.
\end{abstract}

Key words: Stress, elementary education, teachers.

\section{ESTRÉS ENTRE LOS PROFESORES DE LA ENSEÑANZA FUNDAMENTAL DE LAS ESCUELAS PÚBLICAS ESTADUALES}

\begin{abstract}
RESUMEN. El artículo relata investigación que visó, entre otros objetivos, identificar la presencia del estrés, la sintomatología y las fases presentadas por los profesores de la enseñanza fundamental $-1^{\circ}$ a $4^{\circ}$. grados, actuando en escuelas públicas estaduales de una ciudad del interior de São Paulo. 175 profesores participaron de la investigación, atingiéndose aproximadamente $70 \%$ de los profesionales de la Enseñanza Fundamental (PEB-I) actuando en el municipio. Para el logro de los objetivos, dos instrumentos de recogida de datos fueron utilizados: el ISSL (Inventario de Síntomas de Estrés) y un cuestionario para caracterizar a la población estudiada. La investigación reveló que $56.6 \%$ de los profesores están presentando estrés, siendo los principales síntomas: Sensación de desgaste físico constante, cansancio constante, tensión muscular, problemas con la memoria, irritabilidad excesiva, cansancio excesivo, angustia/ansiedad diarias, pensamiento constante en solamente un asunto e irritabilidad sin motivo evidente.
\end{abstract}

Palabras-clave: Estrés, educación fundamental, profesores.

* Doutor em Psicologia. Docente do Departamento de Psicologia - UNESP, Bauru-SP.

\# Professora Titular da Pontifícia Universidade Católica de Campinas - PUCCAMP. 
O ser humano está submetido a mudanças rápidas e significativas em diferentes setores de sua vida. $\mathrm{O}$ ajustamento a essas mudanças vai requerer do indivíduo uma desenvolvida capacidade adaptativa. Haverá forte necessidade de mobilização de energia física, mental e social para que essa adaptação ocorra. No entanto, pode acontecer acentuada incongruência entre sua capacidade de adaptação em relação à velocidade das transformações, gerando uma situação de conflito e desequilíbrio e instalando-se, assim, as situações de estresse. Segundo Lipp e Malagris (2001) e Lipp (2003), o estresse representa um processo complexo do organismo, envolvendo aspectos bioquímicos, físicos e psicológicos, que são desencadeados a partir da interpretação que o indivíduo dá aos estímulos externos e internos - os chamados estressores - causando desequilíbrio na homeostase interna que exige uma resposta de adaptação do organismo para preservação de sua integridade e da própria vida.

O modelo trifásico de evolução do estresse, proposto por Selye em 1956, indica que o processo de estresse, a chamada "síndrome geral de adaptação", compreende três fases: (1) fase de alarme, fase de resistência e fase de exaustão.

A fase de alarme se inicia quando a pessoa se defronta com um estressor. Nesse momento, o organismo se prepara para o que Cannon (1939) designou de "luta ou fuga", com a conseqüente quebra da homeostase. A aceleração do organismo mediante ação aumentada de determinadas funções é, muitas vezes, de grande importância para a preservação da vida, uma vez que leva o organismo a um estado de prontidão, de alerta, a fim de que ele possa atuar em situações de urgência, constituindo uma defesa automática do corpo. O problema surge quando a prontidão fisiológica não é necessária ou quando é excessiva.

A fase de resistência ocorre quando, sendo o estressor de longa duração ou de grande intensidade, o organismo tenta restabelecer o equilíbrio interno de um modo reparador. O organismo se utiliza das reservas de energia adaptativa, na tentativa de se reequilibrar. Se a reserva de energia adaptativa for suficiente, a pessoa se recupera e sai do processo de estresse. Se, por outro lado, o estressor exige mais esforço de adaptação do que é possível para aquele indivíduo, então o organismo se enfraquece e torna-se vulnerável a doenças.
Se a resistência da pessoa não for suficiente para lidar com a fonte de estresse ou se houver concomitantemente a ocorrência de outros estressores, dar-se-á a evolução do processo de estresse, surgindo a fase de exaustão. Então haverá aumento das estruturas linfáticas, poderá ocorrer a exaustão psicológica e a depressão, a exaustão física se manifestará e, como conseqüência, a pessoa poderá desenvolver doenças.

Lipp (2000), ao validar o Inventário de Sintomas de Estresse para adulto de Lipp (ISSL), identificou, tanto clínica como estatisticamente, uma quarta fase, a qual denominou de quase-exaustão, por se encontrar entre as fases de resistência e exaustão. Para a autora, as pessoas não entram em exaustão subitamente, portanto, é de supor a existência de um período de transição antes dessa fase, período em que a pessoa não esteja mais sendo capaz de resistir, mas ainda não tenha atingido a exaustão completa (Lipp, 2004).

Algumas profissões parecem predispor seus profissionais a situações mais estressantes que outras. Por sua natureza, o magistério é, reconhecidamente, uma profissão estressante. No seu cotidiano de trabalho o professor se depara com muitas variáveis que podem contribuir para o desequilíbrio de sua saúde física e mental, levando-o a desenvolver o processo de estresse.

Inúmeras pesquisas foram e estão sendo desenvolvidas, atentando não somente para o processo do estresse ocupacional do professor, mas também para a síndrome de burnout, que acomete esses profissionais no exercício de seu trabalho.

Kryacou e Sutchilffe (1978) e Moracco e Mafadalen (1982) citados por Reinhold (1996) definem o estresse dos professores como uma síndrome de respostas de sentimentos negativos, tais como raiva e depressão, geralmente acompanhadas de mudanças fisiológicas e bioquímicas potencialmente patogênicas, resultantes de aspectos do trabalho do professor e mediadas pela percepção de que as exigências profissionais constituem uma ameaça à sua auto-estima ou bem-estar.

Esteve (1999) classificou os indicadores de malestar dos professores em dois grupos: primário e secundário. No primeiro grupo estão aqueles fatores que incidem diretamente na ação do professor e geram tensões associadas às emoções negativas. Para o autor, o processo de rápidas transformações do contexto social modifica radicalmente o papel do professor, aumentando de forma significativa suas funções e 
responsabilidades. A comunidade e a família passaram a atribuir à escola e à figura do professor funções que muitas vezes os professores não estão preparados para exercer. No segundo grupo, o dos fatores secundários, o autor destaca a falta de recursos pedagógicos (material didático, edifícios e móveis adequados) e a violência nas instituições escolares.

Nunes Sobrinho (2002) ressalta que, no "posto de trabalho" docente, os pesquisadores começam a observar indícios de incompatibilidade entre os limites pessoais do professor e as demandas da população infantil e do sistema educacional, destacando como exemplos o comportamento exibido pelos alunos em sala de aula e as particularidades do atual movimento inclusionista em educação. $\mathrm{O}$ autor denomina "posto de trabalho" do professor o sistema complexo compartilhado por ele: o ambiente físico e social da escola, o tipo de gestão (direção da escola), a organização do trabalho pedagógico, as operações de trabalho, a maneira como o professor administra seu tempo, o manejo do comportamento infantil e o controle do processo ensino-aprendizagem.

Para a implementação de medidas profiláticas e curativas no sentido de minimizar as conseqüências do estresse no professor, necessário se torna verificar sua prevalência e a natureza dos sintomas que incidem nessa classe ocupacional.

\section{MÉTODO}

Dentre outros, o objetivo desta pesquisa foi identificar a presença do estresse, a sintomatologia e as fases do estresse apresentadas pelos professores de $1^{\mathrm{a}}$ a $4^{\mathrm{a}}$ séries do Ensino Fundamental atuantes em escolas públicas estaduais. O projeto de pesquisa foi aprovado pelo Comitê de Ética do HMCP.

\section{Participantes}

Foi contatada a totalidade dos professores que atuam em Educação Básica I (PEB-I) de um município do Interior do Estado de São Paulo. Participaram do estudo 175 professoras da rede pública estadual, efetivas, isto é, que estão no cargo por aprovação em concurso público, e as professoras ACT's (admitidas em caráter temporário), distribuídas em 12 escolas de $1^{\mathrm{a}}$ a $4^{\mathrm{a}}$ séries do Ensino Fundamental. $\mathrm{O}$ número de professoras participantes da pesquisa representa aproximadamente $70 \%$ da totalidade dos professores que atuam nesse segmento educacional da rede pública estadual, no município.

\section{Instrumentos}

Para atingir o objetivo proposto foi utilizado o Inventário de Sintomas de Estresse para Adulto de Lipp (ISSL), que tem como objetivo identificar a sintomatologia apresentada pelas pessoas, avaliando se essas possuem sintomas de estresse, o tipo de sintoma existente (se somático ou psicológico) e a fase do estresse em que se encontram. O ISSL é composto de três quadros, que se referem às quatro fases do estresse (modelo quadrifásico).

Foi utilizado também um questionário de coleta de dados gerais de caracterização dos participantes, composto de 11 questões. Estas questões foram elaboradas para identificação dos dados sociodemográficos (idade, estado civil, número de filhos), aspectos do trabalho (tempo de magistério, tempo de atuação na escola, período de trabalho, se possui outra atividade profissional), opinião sobre o trabalho desempenhado e suas condições, e opinião sobre o estilo de gestão desenvolvido na escola. Para tanto os participantes assinaram o Termo de Consentimento Livre e Esclarecido, explicitando os objetivos e procedimentos da pesquisa e cuidados éticos para sua realização.

\section{Procedimento de coleta de dados}

O primeiro autor fez contato inicial com a Diretoria Regional de Ensino responsável pelas Escolas Estaduais de $1^{\mathrm{a}}$ a $4^{\mathrm{a}}$ série do Ensino Fundamental do município, para apresentar o projeto de pesquisa, e após argüições e pedidos de esclarecimentos, a Dirigente Regional de Ensino autorizou, por meio de declaração formal escrita, que se iniciassem os contatos com as direções das escolas. Caberia ao(à) diretor(a) de cada unidade autorizar ou não a realização da pesquisa, iniciando-se assim uma etapa de agendamentos individuais com esses profissionais para apresentação do trabalho e autorização para contatar os professores.

A totalidade dos diretores das escolas recebeu positivamente o projeto e autorizou o contato com o corpo docente, ficando acordado que caberia a cada professor a decisão de participar ou não na pesquisa. Em consenso, o pesquisador e os diretores de todas as unidades entenderam que o melhor dia e horário para a abordagem dos professores para apresentação do projeto e coleta de dados mediante os dois instrumentos de pesquisa era o da reunião de HTPCs (horário de trabalho pedagógico coletivo). As HTPCs são reuniões semanais obrigatórias, determinadas pela Secretaria da Educação, com duração de duas 
horas/aula, que fazem parte da carga horária de trabalho de todos os professores. A reunião dos docentes num mesmo horário favoreceria as ações de apresentação da pesquisa e esclarecimentos necessários, como também o preenchimento dos instrumentos de pesquisa daqueles que, voluntariamente, se dispusessem participar.

\section{Procedimento de análise dos dados}

As respostas ao Inventário de Sintomas de Estresse para Adulto de Lipp (ISSL) e ao questionário utilizado foram registradas na forma de banco de dados do SPSS for Windows (Statiscal Pakage of Social Science) para viabilizar o desenvolvimento de análises estatísticas.

Como recurso de análise estatística, utilizou-se o teste do Chi-quadrado $\left(\chi^{2}\right)$ para avaliar a significância das diferenças de manifestação de sintomas (físicos e psicológicos) entre as fases do estresse (alerta, resistência, quase-exaustão e exaustão), como também a influência desses sintomas na presença do estresse na categoria profissional pesquisada.

\section{RESULTADOS}

\section{Análise descritiva da população pesquisada}

A Tabela 1 possibilita identificar as faixas etárias, estado civil e número de filhos dos professores participantes. A totalidade dos participantes desse estudo é do sexo feminino.

Tabela 1. Identificação dos Participantes, Conforme Faixa Etária, Estado Civil e Número de Filhos (n/\%).

\begin{tabular}{|c|c|c|}
\hline Variável & $\mathbf{n}$ & $\%$ \\
\hline \multicolumn{3}{|l|}{ Faixa etária (anos) } \\
\hline $20-29$ & 4 & 2,3 \\
\hline $30-39$ & 48 & 27 \\
\hline $40-49$ & 72 & 41,4 \\
\hline 50 anos ou mais & 50 & 28,7 \\
\hline \multicolumn{3}{|l|}{ Estado civil } \\
\hline Casado & 109 & 64,5 \\
\hline Solteiro & 28 & 16,6 \\
\hline Separado & 9 & 5,3 \\
\hline Divorciado & 10 & 5,9 \\
\hline Viúvo & 10 & 5,9 \\
\hline Relação Consensual & 3 & 1,8 \\
\hline \multicolumn{3}{|l|}{ Número de filhos } \\
\hline Sem filhos & 35 & 20,1 \\
\hline 1 a 2 filhos & 89 & 51,1 \\
\hline 3 a 4 filhos & 50 & 28,7 \\
\hline
\end{tabular}

Conforme pode ser visualizado na Tabela 1, a maioria das profissionais entrevistadas $(41,4 \%)$ encontra-se na faixa etária entre 40 e 49 anos, sendo que $28,7 \%$ contam mais de 50 anos. A maior parte da população é casada (64,5\%); 16,6\% são constituídos de solteiras; $11,2 \%$ são divorciadas e/ou separadas, $5,9 \%$ são viúvas e $1,8 \%$ mantém relação consensual. Em relação ao número de filhos, $51,1 \%$ possuem de um a dois filhos; $28,7 \%$ possuem de três a quatro filhos e $20,1 \%$ não possuem filhos.

A Tabela 2 mostra que o tempo de atuação no magistério da maioria dos participantes é de mais de 15 anos, sendo que $42,9 \%$ possuem tempo de atuação entre 15 e 19,9 anos e 25,1\% atuam há mais de 20 anos. Somente $13,7 \%$ da população pesquisada possuem atuação profissional inferior a dez anos.

Em relação às experiências de atuação profissional na escola onde atualmente as professoras se encontram alocadas, a maioria $(54,5 \%)$ possui tempo inferior a quatro anos, $26,7 \%$ têm atuação de quatro a sete anos e nove meses e $18,8 \%$ atuam por períodos de oito anos a mais de dez anos.

Tabela 2. Tempo de Magistério e TEMPO de atuação na Escola dos Respondentes (n/\%).

\begin{tabular}{ccc}
\hline Variável & $\mathbf{n}$ & $\boldsymbol{\%}$ \\
\hline Tempo de magistério (anos) & & \\
$0-4,9$ & 2 & 1,1 \\
$5-9,9$ & 22 & 12,6 \\
$10-14,9$ & 32 & 18,3 \\
$15-19,9$ & 75 & 42,9 \\
+20 & 44 & 25,1 \\
Tempo de atuação na escola (anos) & & \\
$0-1,9$ & 56 & 33,9 \\
$2-3,9$ & 34 & 20,6 \\
$4-5,9$ & 33 & 20 \\
$6-7,9$ & 11 & 6,7 \\
$8-9,9$ & 18 & 10,9 \\
+10 & 13 & 7,9 \\
\hline
\end{tabular}

Quanto ao nível de escolaridade dessas profissionais, $74,1 \%$ possuem nível superior completo - portanto, a maioria da população; $23,7 \%$ possuem nível médio completo e somente $2,2 \%$ fizeram pósgraduação. A maior parte das professoras $(70,3 \%)$ atua profissionalmente só na escola estadual atual, não possuindo outra atividade de trabalho. Em relação ao período de trabalho na escola, há um equilíbrio entre o período matutino, em que atuam $46,0 \%$ das professoras, e o período vespertino, em que atuam outros $44,8 \%$ da população. Somente $9,2 \%$ das professoras têm atividade de docência em ambos os períodos. 


\section{Resultado do Inventário de Sintomas de Estresse para Adulto de Lipp (ISSL)}

Conforme pode ser visto na Tabela 3, o resultado do ISSL revela que $56,6 \%$ das professoras avaliadas estão experimentando estresse. Ao analisar a presença de estresse e as características da população pesquisada, identifica-se que, em relação ao estado civil, das 109 professoras casadas, 56,8\% apresentam estresse. Esta percentagem cai para 50\% na amostra de 28 professoras solteiras e se eleva para $66,5 \%$ dentre as nove professoras separadas. A porcentagem de professoras com estresse é ainda maior dentre as divorciadas, das quais $80 \%$ apresentam estresse. Das dez professoras viúvas, $30 \%$ apresentam estresse, e das três professoras que vivem em relação consensual, $33,3 \%$ apresentam esse mal. Comparadas as diferenças entre a presença e ausência de estresse, em termos percentuais, verifica-se que o número de professoras separadas e divorciadas com estresse é significantemente maior em comparação com as que não possuem estresse dessas categorias.

Tabela 3. Presença ou Ausência de Estresse na População, e sua Distribuição Segundo Estado Civil e Numero de Filhos (n/\%).

\begin{tabular}{|c|c|c|c|c|}
\hline \multirow{3}{*}{ Variável } & \multicolumn{4}{|c|}{ Presença de estresse } \\
\hline & \multicolumn{2}{|c|}{ Sim } & \multicolumn{2}{|c|}{ Não } \\
\hline & $\mathrm{n}$ & $\%$ & $\mathrm{n}$ & $\%$ \\
\hline \multicolumn{5}{|l|}{ Estado civil } \\
\hline Casado & 62 & 56,8 & 47 & 43,2 \\
\hline Solteiro & 14 & 50 & 14 & 50 \\
\hline Separado & 6 & 66,6 & 3 & 33,3 \\
\hline Divorciado & 8 & 80 & 2 & 20 \\
\hline Viúvo & 3 & 30 & 7 & 70 \\
\hline Relação Consensual & 1 & 33,3 & 2 & 66,6 \\
\hline \multicolumn{5}{|l|}{ Número de Filhos } \\
\hline Sem filhos & 13 & 37,1 & 22 & 62,8 \\
\hline 1 a 2 filhos & 50 & 56,1 & 39 & 43,8 \\
\hline 3 a 4 filhos & 36 & 72 & 14 & 28 \\
\hline
\end{tabular}

Em relação ao número de filhos, analisando a presença e ausência de estresse na população, identifica-se que, em termos proporcionais, quanto maior o número de filhos maior é também o número de professoras que apresentam estresse, ou seja, das 35 professoras que não têm filhos, $37,1 \%$ apresentam estresse. Por outro lado, do grupo de 89 professoras que possuem de 1 a 2 filhos, 56,1\% apresentam estresse, e das 50 professoras que possuem de 3 a 4 filhos, $72 \%$ apresentam estresse.

Ao considerar-se o tempo de atuação no magistério, constata-se que há um número maior de professoras com estresse entre aquelas que atuam nesse segmento por períodos entre 10 e 14,9 anos, quando comparadas a grupos com menor tempo de atuação (0 a 4,9 anos e 5 a 9,9 anos) e grupos com maior tempo de atuação (15 a 19,9 anos e mais de 20 anos).

Pesquisando-se se essa população possui outra atividade profissional além da função de professor de ciclo básico I (PEB-I), constata-se que 70,2\%, atuam somente na escola atual, não possuindo outra atividade profissional. Desse grupo, $56 \%$ apresentam estresse, enquanto do grupo de 52 professoras que exercem outra atividade profissional além da mencionada, $56 \%$ apresentam estresse. Pode-se verificar que, percentualmente, o nível de presença/ausência de estresse é o mesmo para ambos os grupos.

Dentre as 99 professoras pesquisadas que apresentam estresse, $80,8 \%$ encontram-se na fase de resistência, $17,2 \%$ estão na fase de quase-exaustão e duas professoras (2\%) na fase de exaustão.

Em $27,3 \%$ das profissionais predominam os sintomas físicos e em $13,1 \%$ foram constatada presença acentuada de ambos os sintomas, indicando que essa população está mais vulnerável a problemas relacionados a sintomas psicológicos $(59,6 \%$ das participantes).

As Figuras 1 e 2 apresentam os principais sintomas manifestados pelas docentes que se encontram nas fases de resistência e de quaseexaustão, fases na qual se encontra a quase-totalidade das professoras estressadas, ou seja, $98 \%$.

A Figura 1 apresenta os principais sintomas que se manifestam na grande maioria das professoras com estresse, ou seja, aquelas que se encontram na fase de resistência.

Em relação aos sintomas físicos que estão sendo manifestados, destacam-se: sensação de desgaste físico constante, cansaço constante, tensão muscular e problemas com a memória. Os três primeiros sintomas indicam que, provavelmente, as atividades originadas da função estudada podem caracterizar-se como atividades desgastantes no que se refere às exigências físicas e resistência do organismo das professoras. 

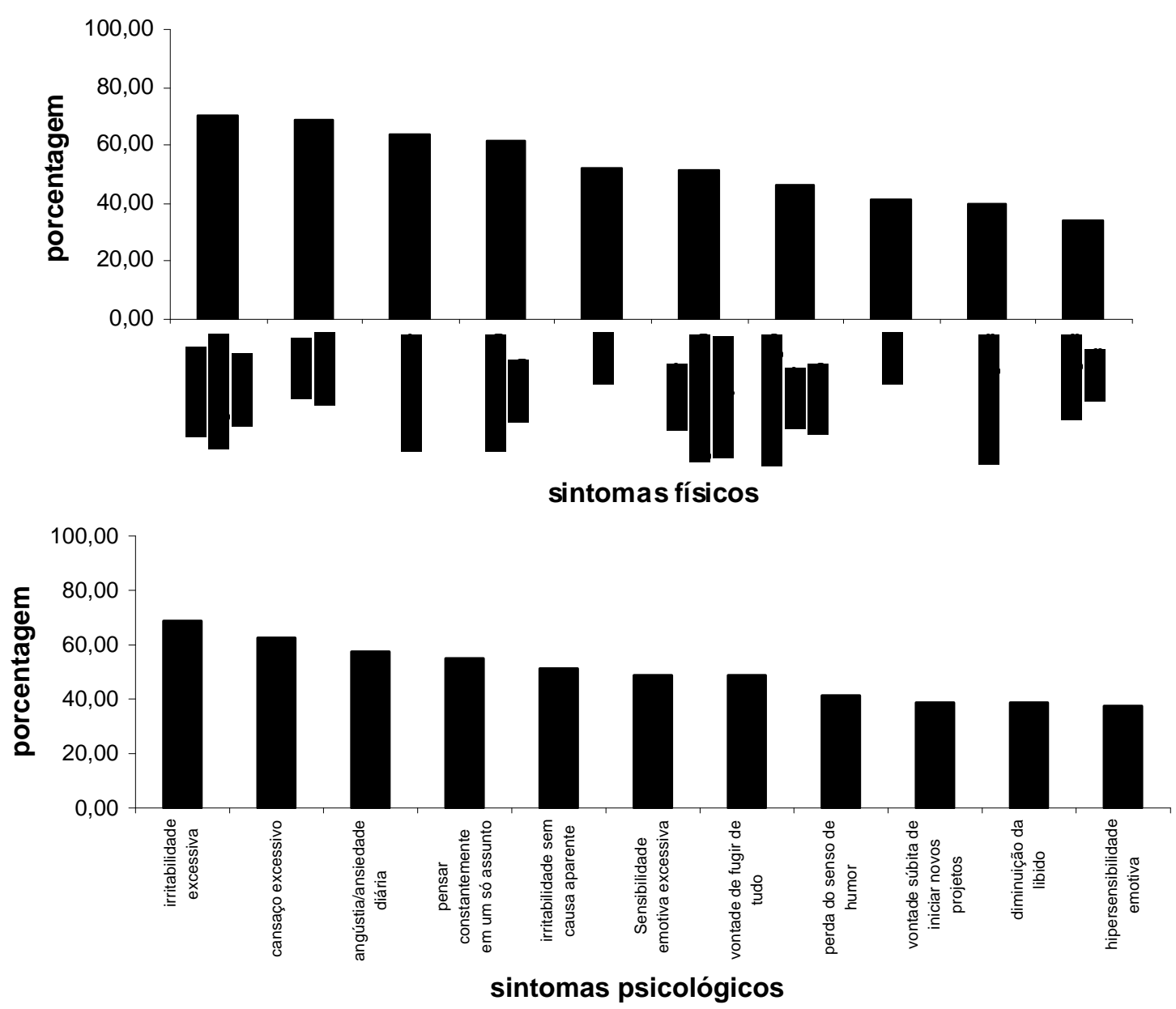

Figura 1. Principais Sintomas da População Estudada em Fase de Resistência.

Em relação ao quarto principal sintoma físico em destaque - problemas com a memória - conjetura-se que pode estar trazendo consideráveis problemas para aquelas que o experimentam, uma vez que atividades de memorização são intrínsecas às exigências da função docente.

Em relação aos sintomas psicológicos, irritabilidade excessiva, cansaço excessivo, angústia/ansiedade diária, pensar constantemente em um só assunto e irritabilidade sem causa aparente destacam-se como os sintomas psicológicos mais presentes na população pesquisada que se encontra na fase de resistência. Sensibilidade emotiva excessiva e vontade de fugir de tudo são sintomas que também estão presentes, embora em um grau menor.

A Figura 2 apresenta os principais sintomas manifestados em $17,2 \%$ das professoras que apresentam estresse e se encontram na fase de quaseexaustão. Constata-se que os principais sintomas tanto os físicos como os psicológicos - das profissionais que estão nessa fase são semelhantes aos principais sintomas apresentados pelo grupo das professoras que estão na fase anterior, ou seja, na fase de resistência. Tal fato pode estar indicando que, para essa população que está na fase de quase-exaustão, os sintomas estão se manifestando com maior intensidade e constância.

Comparando-se as professoras que estão nas duas fases apresentadas - resistência e quase-exaustão constata-se que os sintomas físicos apresentados são os mesmos para ambas as fases, para na população que está em quase-exaustão eles estão presentes numa porcentagem mais significativa de indivíduos; por exemplo, os principais sintomas apresentados no grupo de quase-exaustão são experienciados por aproximadamente $97 \%$ das professoras, enquanto esses mesmos sintomas se manifestam em $70 \%$ dos indivíduos que estão na fase de resistência. $\mathrm{Na}$ fase de quase-exaustão os sintomas presentes na resistência se agravam, dando margem ao aparecimento de várias doenças. 

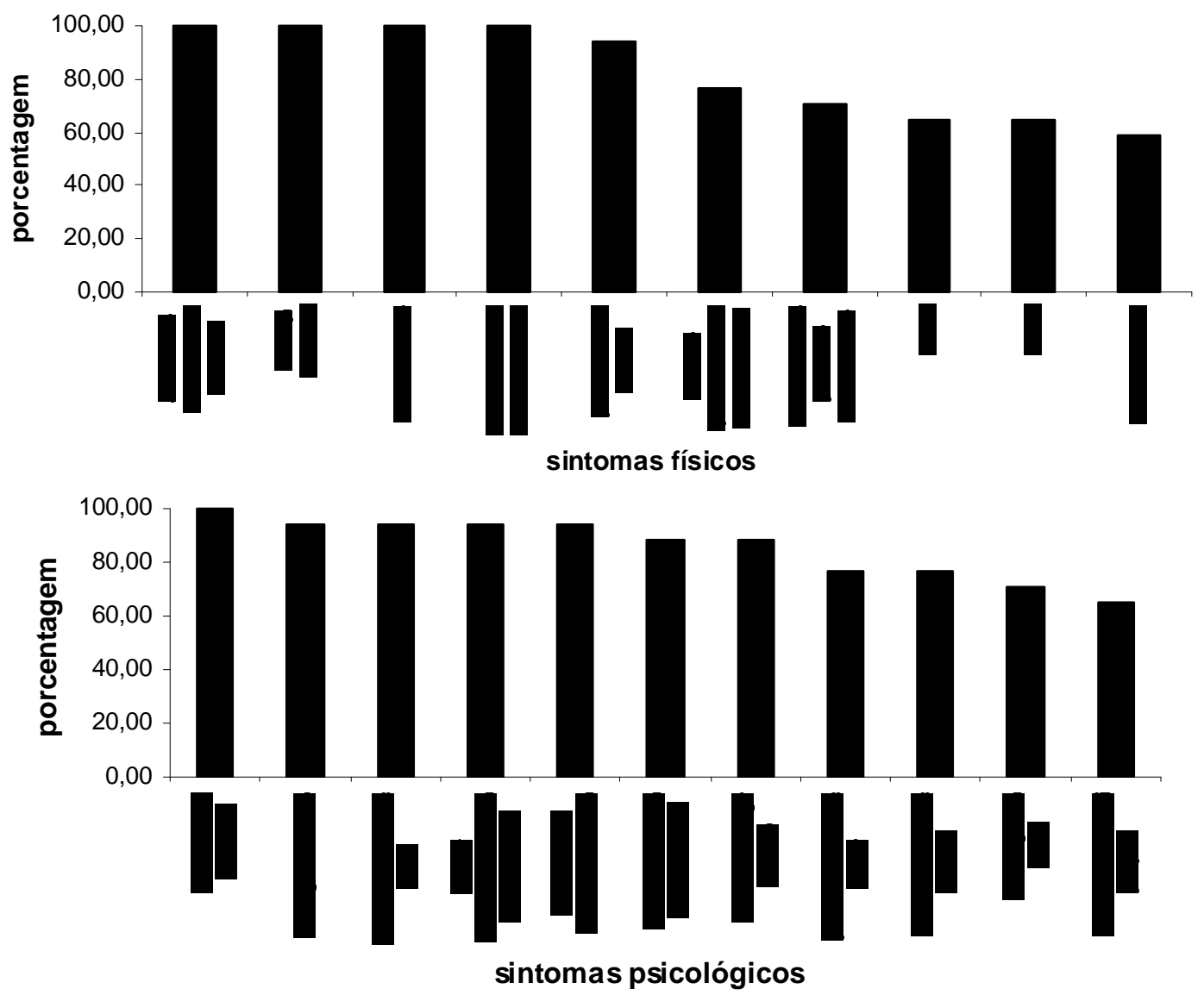

Figura 2. Principais Sintomas da População Estudada em Fase de Quase-Exaustão.

Outros sintomas físicos são identificados nos dois grupos, conforme as Figuras 1 e 2 . O único sintoma físico que é específico do grupo da fase de resistência é mudança de apetite, que acomete aproximadamente $37 \%$ das pessoas nessa fase. Em contrapartida, o aparecimento de problemas dermatológicos é específico do grupo que se encontra na fase de quaseexaustão, manifestando-se em aproximadamente $70 \%$ das professoras.

Ao analisar a manifestação dos sintomas psicológicos, constata-se que o fenômeno se repete, ou seja, os sintomas manifestados pelos dois grupos são, em sua maioria, os mesmos; portém os percentuais de todos os sintomas avaliados foram mais elevados no grupo de professoras na fase de quase-exaustão do que no de professoras da fase de resistência. Irritabilidade excessiva, cansaço excessivo, angústia, ansiedade diária e pensar constantemente em um só assunto são os principais sintomas psicológicos manifestados nos indivíduos dos dois grupos. Para aqueles que estão na fase de quase-exaustão, eles manifestam-se em aproximadamente $95 \%$ da população, e em aproximadamente $65 \%$ da população que se encontra na fase de resistência.
Excepcionalmente, $70 \%$ dos indivíduos que estão em quase-exaustão manifestam o sintoma dúvida quanto a si próprio, o qual não aparece no grupo na fase de resistência. Vontade súbita de iniciar novos projetos é um sintoma manifestado somente em $40 \%$ das professoras que estão na fase de resistência.

Espera-se - e é até natural - que pessoas experienciem algum tipo de desconforto eventual que se encontre dentro do elenco de sintomas regulares do estresse, o que não implica que isso tenha significado clinico para se diagnosticar a presença do estresse, nem que deva ser assim interpretado. $O$ que caracteriza o estresse é a presença de um quadro sintomatológico composto por diversos itens que se prolongam por certo período de tempo. Sendo assim, estudos estatísticos foram realizados no sentido de identificar o quadro sintomatológico apresentado e sua influência na presença do estresse nas participantes do estudo.

A prova do Chi-quadrado identifica que os sintomas tensão muscular, mal-estar generalizado, pensar constantemente em um só assunto, diminuição da libido, vontade de fugir de tudo e irritabilidade sem causa aparente apresentam diferenças 
significativas entre as fases e demonstram ter influência na presença do estresse nas professoras $(p<0,05)$. Por outro lado, embora a prova do Chiquadrado tenha mostrado que os sintomas aumento da sudorese, hiperventilação, diarréia constante e hipertensão arterial continuada também apresentam diferenças significativas entre as fases $(p<0,05)$, eles possuem baixa influência na presença do estresse nas professoras. A análise estatística revela que os sintomas problemas com a memória, sensação de desgaste físico constante, cansaço constante, sensibilidade emotiva excessiva, irritabilidade excessiva e angústia/ansiedade diária apresentam acentuada diferença entre as fases do estresse e têm alta influência na presença do estresse nas docentes $(p<0,01)$.

O sintoma dúvida quanto a si próprio, embora apresente significativa diferença entre as fases, tem baixa influência na presença do estresse em professoras que se encontram na fase de resistência e forte influência em professoras que se encontram na fase de quase-exaustão. O mesmo acontece com os sintomas sensação de incompetência em todas as áreas, hipersensibilidade emotiva, perda de senso de humor e dificuldades sexuais, ou seja, baixa influência na presença de estresse em indivíduos que se encontram na fase de resistência e forte influência na presença de estresse naqueles que se encontram na fase de quase-exaustão, em um grau menos acentuado de diferenciação entre as fases $(p<0,05)$.

\section{DISCUSSÃO}

A totalidade da população pesquisada é do sexo feminino, sendo que em sua maioria essas profissionais estão na faixa etária que varia entre $30 \mathrm{e}$ 49 anos, são casadas $(64,5 \%)$ e possuem de um a dois filhos $(51,1 \%)$. A maior parte das participantes possui experiência profissional significativa, ou seja, 42,9\% atuam no magistério por um período entre 15 e 19,9 anos, e 25,1\% estão nessa profissão há mais de 20 anos. Esses dados nos permitem inferir que são profissionais experientes em sua área de atuação.

Considerando-se o tempo de atuação na escola atual à qual pertencem, a maioria das professoras possui tempo médio de quatro anos, tempo considerado suficiente para o desenvolvimento de uma compreensão adequada e um diagnóstico geral sobre questões do contexto de trabalho, como o perfil da clientela atendida, o clima organizacional existente, as relações que são estabelecidas, as necessidades operacionais de trabalho, entre outras.
Pode-se conjeturar que as professoras participantes possuem formação acadêmica suficiente para o bom desempenho da função exercida, uma vez que, além da importante experiência profissional, a grande maioria $(74,1 \%)$ possui nível superior completo, predominando quase exclusivamente a formação em Pedagogia.

As participantes desse estudo estão distribuídas em 12 escolas estaduais do Ensino Fundamental. Essas escolas apresentaram, em alguns casos, acentuada heterogeneidade no que se refere ao tamanho, estrutura física, número de alunos, e, conseqüentemente, de salas de aula, número de professores, localização e número de profissionais de apoio. O que é semelhante entre elas é o perfil da clientela atendida, ou seja, crianças oriundas de famílias de classe social baixa, com todas as implicações daí decorrentes. Outro fator semelhante é a existência de uma direção escolar que responde pela parte administrativa, jurídica e pedagógica da escola. A existência de vice-direção e coordenação pedagógica está vinculada diretamente ao número de salas de aula de cada escola.

Constata-se que 99 das 175 professoras participantes do estudo apresentam estresse, perfazendo o percentual de $56,6 \%$ da população, do qual $80,8 \%$ se encontram na fase de resistência. Os resultados revelam que a maioria das professoras experimenta estresse, resultado semelhante aos obtidos por Rossa (2004), que, ao pesquisar 62 professores voluntários do Ensino Médio e Fundamental de outra cidade do Interior do Estado de São Paulo, constatou a presença de estresse em $58,1 \%$ da população, sendo que na maior parte dos casos $(72,7 \%)$ este estava na fase resistência.

A alta incidência do estresse em professores indica a presença de um nível significativo e acentuado de tensão, o que pode dar oportunidades à ocorrência de doenças, devido à redução do seu sistema imunológico e suas conseqüências. Importante ressaltar que, segundo Lipp e Malagris (1995), na fase de resistência do estresse o organismo atua no sentido de buscar se reequilibrar, ocorrendo uma grande utilização de energia, o que pode gerar sensação de desgaste generalizado sem causa aparente e dificuldades com a memória, dentre outras conseqüências. Quanto maior o esforço que o indivíduo faz para se adaptar e restabelecer o equilíbrio interior, maior é o desgaste do organismo. Quando o organismo consegue harmonizar-se e resistir adequadamente ao estressor, o processo do estresse se interrompe sem sequielas. Essa fase do estresse possibilita às pessoas aprenderem a lidar com 
as tensões que estão abalando seu equilíbrio interno a partir de intervenções individuais e coletivas adequadas, o que vai minimizar e/ou eliminar os sintomas presentes.

Embora em menor número $(17,2 \%)$, parte das professoras se encontra na fase de quase-exaustão, indicando uma evolução do estresse em relação àquelas da fase anterior, ou seja, a fase de resistência. Os resultados revelam que essas profissionais começam a ceder e já não conseguem resistir às tensões e restabelecer o equilíbrio interior. Para Lipp (2004), ocorre alternância entre momentos em que os indivíduos conseguem resistir às pressões e tensões do cotidiano e se sentem razoavelmente bem, e momentos de desconforto, cansaço e ansiedade. Nessa fase, algumas doenças começam a aparecer, o que demonstra que sua resistência já não está tão eficaz.

A pesquisa mostra que, em termos proporcionais, as professoras divorciadas e separadas são as categorias que mais acentuadamente apresentam estresse, havendo certo equilíbrio entre presença e ausência do estresse em professoras casadas e solteiras. Ainda em relação ao estado civil, as professoras viúvas e aquelas que vivem em relação consensual são as menos expostas ao estresse. A presença do estresse em um número maior de professoras separadas e divorciadas talvez tenha relação com os múltiplos papéis sociais que elas precisam assumir, principalmente relacionados à vida pessoal. Soma-se a isso um implícito processo de discriminação e preconceito que ainda persiste na sociedade, embora em níveis inferiores nos dias atuais, fatores que podem se constituir em estresse adicional.

Da constatação de que, proporcionalmente, quanto maior a quantidade de filhos, maior é o número de professoras apresentando estresse, infere-se que essa questão pode também se configurar como fator de estresse adicional nas profissionais pesquisadas.

Quanto ao tempo de atuação das professoras no magistério, o período que varia entre 10 e 14,9 anos parece caracterizar-se como uma faixa crítica de atuação do professor, uma vez que se verificou uma maior presença do estresse nas profissionais com esse tempo de docência. O fenômeno constatado talvez se explique pelo fato de as professoras com esse tempo de atuação profissional não se encontrarem em início de carreira, quando as expectativas positivas, motivações e aspirações ainda estão fortemente presentes, nem em estágios finais de carreira, quando está presente um significativo tempo de experiência, que contribui para lidar melhor com as adversidades da profissão, ou até mesmo a expectativa de deixar de atuar pela chegada da aposentadoria profissional.
O objetivo do trabalho não foi investigar diferenças do nível de estresse relacionadas ao estado civil, número de filhos e tempo de magistério das professoras, por isso não se focou maior atenção na busca de dados que pudessem explicar melhor os resultados obtidos, segundo os quais o estresse aparece em maior número de professoras sob essas circunstâncias. Destarte as hipóteses indicadas nos parágrafos anteriores são explicativas e objetivam facilitar e ampliar a compreensão dos resultados da pesquisa, bem como sinalizar caminhos para novos estudos. Faz-se necessário efetuar outras verificações que possam confirmar esses resultados e explicá-los de forma mais profunda.

Embora os resultados sobre a presença do estresse estejam sendo interpretados no contexto do estresse ocupacional, cumpre considerar que quem participou dessa pesquisa como respondente eram pessoas do sexo feminino. Esse fato poderia ser também considerado, pelo menos parcialmente, como uma das razões do alto índice de estresse detectado. Autores têm apontado para uma maior ocorrência de estresse entre mulheres, quando comparada com a presença do estresse em homens (Calais, Andrade \& Lipp, 2003; Lipp, 2001, 2004; Scott, 1992). Calais et al. (2003) indicam a existência de inúmeras razões para se acreditar que o desenvolvimento evolutivo, biológico e social esteja influindo nessa questão, por exemplo, uma sensibilidade maior ao estresse entre as mulheres, embora salientem, segundo indicam pesquisas recentes, diferenças sexuais, nessa vulnerabilidade, são altamente específicas e dependem do tipo do estressor e da desordem envolvidos.

A constatação da predominância de sintomatologia de ordem psicológica nas professoras que experimentam estresse parece indicar que essa população é mais vulnerável a esse fenômeno, embora a pesquisa tenha revelado também a presença de sintomas físicos.

Irritabilidade excessiva, cansaço excessivo, angústia/ansiedade diária, pensar constantemente em um só assunto e irritabilidade sem causa aparente se configuraram como os principais sintomas de ordem psicológica para as professoras que se encontram na fase de resistência, enquanto para aquelas que estão na fase de quase-exaustão prevaleceram os mesmos sintomas citados acima, com exceção de irritabilidade sem causa aparente. Deve-se considerar que os sintomas manifestados estão presentes em um maior número de professoras em fase de quase-exaustão, se comparadas com as que se encontram na fase de resistência. 
A presença de quadro sintomatológico de ordem psicológica, provavelmente, esteja influenciando negativamente as relações interpessoais que as professoras devem estabelecer com a comunidade escolar, com destaque para aquelas que devem manter com o corpo discente da escola. Deve-se ressaltar que o relacionamento adequado entre professor e aluno é condição essencial para o sucesso da relação ensinoaprendizagem, principalmente nos primeiros ciclos acadêmicos, ou seja, o Ensino Fundamental.

Deve-se também considerar que o quadro de sintomas apresentado talvez possa estar influenciando negativamente na qualidade da comunicação assertiva, tão necessária às atividades docentes, como também no nível de motivação do professor e no grau de satisfação com o trabalho. A diminuição da motivação para o trabalho e da satisfação em exercer a função docente pode contribuir não somente para minimizar o desempenho profissional e os resultados da escola, mas, sobretudo, para o agravamento do quadro do estresse ocupacional.

Embora não de forma predominante, a pesquisa revelou que sintomas físicos estão se manifestando nas professoras que experimentam estresse e devem ser considerados, pois é muito provável que eles também estejam influenciando negativamente o desempenho pessoal e profissional da população pesquisada. Sensação de desgaste físico constante, cansaço constante, tensão muscular e problemas com a memória são os sintomas de ordem física que se destacaram, acometendo professoras que se encontram em ambas as fases (resistência e quase-exaustão).

Pode-se considerar que as professoras que se encontram na fase de resistência e experienciam os mesmos sintomas manifestados pelo grupo da fase de quase-exaustão, se não receberem a devida atenção no que se refere ao manejo e controle do estresse, podem caminhar com certa rapidez para essa fase posterior, ou seja, a de quase-exaustão, agravando o quadro de estresse apresentado no momento.

$\mathrm{O}$ único sintoma físico específico encontrado no grupo em fase de resistência é mudança de apetite, que acomete aproximadamente $37 \%$ das professoras; e em contrapartida, o aparecimento de problemas dermatológicos é específico do grupo da fase de quase-exaustão, manifestando-se em aproximadamente $70 \%$ das professoras, indício evidente de que nessa fase do estresse os problemas começam a se intensificar com mais força.

Importante ressaltar que o trabalho do professor ocupa grande parte, se não a maior parte de seu tempo, sendo que o ritmo desse trabalho, na maioria das vezes, costuma ser intenso, exigindo elevados índices de atenção e concentração para a realização das tarefas e cumprimento de metas pedagógicas e administrativas, principalmente em se considerando a atuação do professor de Ensino Fundamental. Como afirma Meleiro (2002), é praticamente ele que inicia a socialização das crianças, representando papel fundamental nas fases de seu desenvolvimento. Essas questões preliminares, somente para ilustrar a complexidade da função desses profissionais e as responsabilidades originadas da atuação docente, exigem acentuado equilíbrio emocional e físico por parte de quem escolhe essa profissão.

A presença do quadro sintomatológico apresentado, tanto físico como psicológico, talvez esteja influenciando negativamente o desempenho dessas profissionais, como, provavelmente, influencie negativamente o alcance das metas e objetivos da instituição escolar. A negligência em relação a esse fenômeno acentuará uma tendência de piora, principalmente para aquelas professoras que, por suas características, têm mais dificuldades em lidar com estressores do contexto escolar, e, por conseqüência, estão mais vulneráveis ao estresse.

Importante se faz esclarecer que as citações feitas sobre os sintomas apresentados pelas professoras e as conseqüências no desempenho profissional são conjeturas que necessitam de estudos mais específicos para sua confirmação ou não.

\section{CONCLUSÃO}

O presente trabalho veio confirmar outros estudos que apontam a presença do estresse em profissionais da Educação, principalmente professores que atuam no Ensino Fundamental.

$\mathrm{O}$ fenômeno tem se mostrado cada vez mais crescente, sinalizando a necessidade premente de diagnosticar suas causas por meio de estudos específicos, bem como seu impacto nas atividades profissionais e na qualidade de vida dos professores. Necessário também se faz identificar e mensurar a presença do estresse nos professores e sua influência nos resultados e metas das instituições escolares, na aprendizagem e desenvolvimento dos alunos e nos objetivos maiores da política educacional vigente.

Certos estressores presentes no cotidiano do trabalho do professor estão fora de seu controle direto e são determinados pelas políticas educacionais, que vão regular o funcionamento da escola em geral, como também aspectos mais específicos relacionados a estratégias pedagógicas e conteúdos teóricos que serão trabalhados com os alunos. A definição dessas políticas e diretrizes educacionais ocorre, quase 
sempre, sem o envolvimento direto do professor, negligenciando limites, capacidades, necessidades e motivação do docente, condições imprescindíveis para o adequado e saudável exercício profissional.

A maioria das professoras que experimentavam estresse esteve na fase de resistência, indicando que, embora presente um nível elevado de tensão, ocasionando o surgimento de sintomas, o quadro ainda permite o manejo dessas tensões, com as quais essas pessoas poderão aprender a lidar a partir de intervenções e orientações adequadas. No entanto, se nada for feito, é muito provável que ocorra em pessoas mais vulneráveis um processo de evolução, agravando o estresse e tornando mais complexas as intervenções. Estágios mais avançados do estresse (quase-exaustão e exaustão) vão intensificar o surgimento de sintomas, tanto de ordem física como psicológica, o que vai afetar, na mesma proporção, o desempenho pessoal e profissional das professoras.

Esses e outros estudos revelam que os professores, pela complexidade e responsabilidade de sua atuação, estão expostos a inúmeros fatores, que, dependendo das suas características pessoais, podem ou não abalar seu equilíbrio interno. Nem sempre esses profissionais têm condições e recursos próprios para lidar adequadamente com essas situações. O cenário se agrava, uma vez que as escolas não disponibilizam para os professores nenhum tipo de suporte profissional, seja este de ordem psicológica ou médica, de modo que, em muitos casos, eles se vêem sozinhos no enfrentamento de problemas que estão afetando sua saúde e bem-estar.

Evidenciou-se, assim, a necessidade urgente de políticas voltadas à realização de trabalhos preventivos e/ou de tratamento destinados às professoras, como meio de amenizar a tensão ocupacional, bem como de ações que venham ao encontro de suas necessidades e expectativas, elevando sua motivação e auto-estima e tornando-as mais fortes, mais capacitadas e preparadas para os desafios da atuação profissional.

\section{REFERÊNCIAS}

Calais, S. L., Andrade, L. M. B., \& Lipp, M. E. N. (2003). Diferenças de sexo e escolaridade na manifestação do stress em adultos jovens. Psicologia: Reflexão e Crítica, 16(2), 257-263.
Cannon, W. B. (1939). The wisdom of the body. Nova York: Norton.

Esteve, J. M. (1999). O mal-estar docente: a sala de aula e a saúde dos professores. Bauru: EDUSC.

Lipp, M. E. N., \& Malagris, L. N. (1995). Manejo do stress: psicoterapia comportamental e cognitiva. Campinas: Psy II.

Lipp, M. E. N., \& Malagris, L. E. N. (2001). O stress emocional e seu tratamento. Em B. Rangé (Org.), Psicoterapias cognitivocomportamentais. Rio de Janeiro: Artmed.

Lipp, M. E. N. (1996). Stress: conceitos básicos. Em M. E. N. Lipp (Org.), Pesquisas sobre o stress no Brasil: saúde, ocupações e grupos de risco (pp. 17-31). Campinas: Papirus.

Lipp, M. E. N. (2000). Inventário de sintomas de stress para adulto de Lipp - ISSL. São Paulo: Casa do Psicólogo.

Lipp, M. E. N. (2001). Estresse emocional e contribuição de estressores internos e externos. Revista Psiquiatria Clínica, 28(6), 347-349.

Lipp, M. E. N. (2003). Mecanismos neuropsicofisiológicos do stress: teoria e aplicações clínicas. São Paulo: Casa do Psicólogo.

Lipp. M. E. N. (2004). Stress emocional: esboço da teoria de "Temas de Vida". Em M. E. N. Lipp (Org.), O stress no Brasil: pesquisas avançadas (pp. 17-30). Campinas: Papirus.

Meleiro, A. M. S. (2002). O stress do professor. Em M. E. N. Lipp (Org.), O stress do professor (pp. 11-27). Campinas, SP: Papirus.

Nunes Sobrinho, F. C. (2002). O stress do professor do ensino fundamental: o enfoque da ergonomia. Em M. E. N. Lipp (Org.), O stress do professor (pp. 81-94). Campinas, SP: Papirus.

Reinhold, H. H. (1996). Stress ocupacional do professor. Em M. E. N. Lipp (Org.), Pesquisas sobre stress no Brasil: saúde, ocupações e grupos de risco (pp. 169-194). Campinas, SP: Papirus.

Rossa, E. G. O. (2004). Relação entre stress e burnout em professores de ensino fundamental e médio. Em M. E. N. Lipp (Org.), O stress no Brasil: Pesquisas avançadas (pp. 131-138). Campinas, SP: Papirus.

Scott, N. A. (1992). Chief student affairs officers: Stress and strategies. Journal of College Student Development, 33, 108116.

Recebido em 08/12/2006 Aceito em 16/04/2007

Endereço para correspondência : Edward Goulart Junior. Rua Célio Daibém, 11-37 - Altos da Cidade, CEP 17014-270, Bauru-SP E-mail: edward@fc.unesp.br 